\title{
Value of biomarkers in the diagnosis of community- acquired pneumonia with concomitant chronic heart failure: a prospective observation study.
}

\section{Svetlana Rachina ( $\square$ Svetlana.Ratchina@antibiotic.ru )}

Rossijskij universitet druzby narodov Medicinskij institut https://orcid.org/0000-0002-3329-7846

\section{Andrey Bobylev}

Smolenskij gosudarstvennyj medicinskij universitet

\section{Sergey Avdeev}

Pervyj Moskovskij gosudarstvennyj medicinskij universitet imeni I M Secenova

\section{Roman Kozlov}

Smolenskij gosudarstvennyj medicinskij universitet

\section{Pavel Lazarev}

Rossijskij universitet druzby narodov Medicinskij institut

\section{Vladimir Mladov}

BIOCAD CJSC Saint-Petersburg

\section{Yulia Khruleva}

Rossijskij universitet druzby narodov Medicinskij institut

\section{Research article}

Keywords: community-acquired pneumonia, chronic heart failure, inflammatory biomarkers

Posted Date: January 9th, 2020

DOI: https://doi.org/10.21203/rs.2.20488/v1

License: (9) This work is licensed under a Creative Commons Attribution 4.0 International License. Read Full License 


\section{Abstract}

\section{Background}

The diagnosis of community-acquired pneumonia (CAP) in patients with chronic heart failure (CHF) is associated with objective difficulties due to similar clinical presentation. We aimed to evaluate the utility of serum biomarkers - C-reactive protein (CRP), procalcitonin (PCT), tumour necrosis factor a (TNFa), interleukin-6 (IL-6) and brain natriuretic peptide (BNP) in diagnosis of CAP in the presence of CHF.

\section{Methods}

Prospective observational study included patients with previously diagnosed CHF and suspected nonsevere CAP. Participants underwent routine procedures and chest multispiral computed tomography (MSCT); serum levels of biomarkers (CRP, PCT, TNFa, IL-6) and BNP were measured. All patients were divided into group 1 with confirmed CAP and group 2 with excluded CAP according to MSCT findings. Standard statistical tools were applied, $p$-value $<0.05$ in two-tailed tests was considered statistically significant. The value of biomarkers was determined using logistic regression, their discriminatory efficacy was assessed by analyzing Receiver Operation Characteristic (ROC) curves.

Results

Altogether 35 with CAP (median age 78 (64-82) years, female 24/35 (68.6\%)) and 35 - without CAP (median age 77 (71-82) years, female 22/35 (62.9\%)) were enrolled. There were no differences between groups in baseline characteristics, with the exception of body temperature. We found significantly higher levels of CRP 50.0 (35.5-98.5) mg/L, PCT 0.10 (0.05-0.54) ng/mL and IL-6 46.1 (21.4-150.3) pg/mL in group 1 as compared to group 2 - 15.0 (9.5-25.0) mg/L, $0.05(0.05-0.05) \mathrm{ng} / \mathrm{mL}$ and 13,6 $(9,5 ; 25,0)$ $\mathrm{pg} / \mathrm{mL}$, respectively. AUC $(95 \% \mathrm{Cl})$ was the highest for CRP -0.91 (0.83-0.98), followed by PCT -0.81 $(0.72-0.90)$ and IL-6 $-0.81(0.71-0.91)$. CRP value of $28.5 \mathrm{mg} / \mathrm{L}$ had optimal sensitivity and specificity ratio $(85.7 / 91.4 \%)$.

\section{Conclusion}

The measurement of serum CRP, PCT, IL-6 levels can be useful for diagnostics of CAP in patients with concomitant CHF. CRP had the optimal diagnostic utility in this population. Key words: communityacquired pneumonia, chronic heart failure, inflammatory biomarkers

\section{Introduction}

The combination of CHF and CAP is mutually extremely unfavorable in terms of both prognosis and clinical course of these diseases. The diagnosis of CAP in CHF patients is also fraught with objective difficulties. CHF symptoms can mask the clinical signs of CAP (1-3). Importantly, typical signs of CHF can be also explained by a new episode of respiratory tract infection (RTI) including CAP (4). 
Conventional chest radiography (X-ray) is distinguished by relatively low specificity for CAP verification in the population of CHF patients (5).

Inflammatory biomarkers are undoubtedly among the crucial molecules in the pathogenesis of CAP, which the most studied are CRP, PCT, tumour necrosis factor a TNFa and interleukins, namely, IL-6.

A number of authors demonstrated significant elevation of serum concentrations of these biomarkers in patients with CAP. The utilized markers of cardiac dysfunction include creatine kinase-muscle/brain, troponins, arginine-vasopressin, copeptin, pro-adrenomedullin, atrial natriuretic peptide and BNP. Parallel measurement of biomarkers of different profiles may prove useful in the cases of coexistent CHF and CAP (6-8).

We aimed to evaluate the role of measurement of serum biomarkers of inflammation (CRP, PCT, IL-6, TNFa) and BNP in the diagnosis of CAP in CHF patients.

\section{Methods}

Our prospective observational study enrolled patients aged over 40 with New York Heart Association functional class II-IV CHF and suspected non-severe CAP from hospitals of Smolensk city (Russian Federation). The protocol was approved by the local institutional review board. Upon enrollment and prior to any procedure relevant to the study, each participant signed two copies of the informed consent form.

All participants underwent conventional procedures including physical examination, lab tests and chest X-ray. The infiltration consistent with pneumonia was confirmed using chest MSCT. Based on the MSCT results, the patients were divided into two groups: with CAP (group 1) and without CAP but having signs and symptoms of other RTI and/or CHF worsening (group 2). CHF diagnosis had to be present for at least 3 months before hospitalization and supported by previous medical documentation (4).

The serum concentrations of CRP, PCT, IL-6, TNFa, and BNP were measured at enrollment. All other diagnostic procedures and treatment decisions regarding both $\mathrm{CHF}$ and CAP were carried out in compliance with local clinical practice.

We measured CRP using photometric turbidimetry immunoassay with semiautomatic analyser Humalyzer 2000 (HUMAN, GmbH, Germany) and HUMAN diagnostic kits. Reference CRP values were $\llbracket 8 \mathrm{mg} / \mathrm{L}$ or equal. PCT was measured using chemiluminescence method with automatic mini-VIDAS analyser (BioMerieux, France) and BioMerieux diagnostic kits (VIDAS BRAHMS). Reference values were

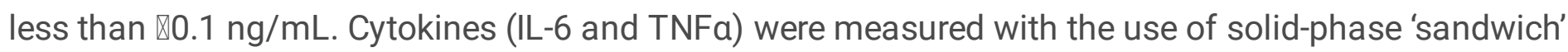
variant of enzyme linked immunosorbent assay (EIA) by means of diagnostic kits Interleukin-6-IFA-Best and alfa-FNO-IFA-BEST (CJSC «Vector Best», Russian Feredation) and Multiscan EX IFA-reader ("Thermo Labsystems», China). IL-6 and TNFa reference values were $<10 \mathrm{pg} / \mathrm{mL}$ or equal, and $<6 \mathrm{pg} / \mathrm{mL}$ or equal, respectively. BNP measurement was made using chemiluminescence method with automatic analyser ADVIA Centaur XP (Siemens, USA), Siemens diagnostic kits (closed system), and assayed BIO-RAD 
controls (USA). Reference values for patients under and over 60 years were $0-80 \mathrm{pg} / \mathrm{mL}$ and 0 $100 \mathrm{pg} / \mathrm{mL}$, respectively.

\section{Statistical analysis}

Statistical data processing was performed with the use of R v.3.3.2 free software environment for statistical computing and graphics (The R Foundation for Statistical Computing, Vienna, Austria). Based on the sample size, the distribution of numerical variables was considered to be abnormal. Summary statistical data are presented as the number of observations, median and interquartile range (IQR) with 25th -75th percentile values. Comparative analyses were performed using non-parametric methods. Intragroup comparisons were carried out by means of Wilcoxon test for paired samples with Holm-Bonferroni adjustment for multiple comparisons. Mann-Whitney test was applied to study inter-group differences of continuous variables. Categorical variables are presented as absolute and relative rates that were compared using Fisher's exact test. The statistical significance of biomarkers in the diagnosis of CAP was determined using logistic regression. First, the independent efficacy of each parameter was measured by constructing univariable predictor models. Discriminatory efficacy was assessed by analyzing ROC curves and was numerically interpreted using Area Under ROC Curve (AUC) values.

All differences were considered to be statistically significant when the p-value was less than the level of significance (0.05) in two-tailed tests.

\section{Results}

Our study included 70 patients with CHF aged 50-90 years: 35 with confirmed CAP (median (IQR) age 78 (64-82) years) and 35 without CAP (median age 77 (71-82) years). The majority of patients in groups were female: $24 / 35$ (68.6\%) and 22/35 (62.9\%), respectively. Baseline demographic, history and clinical characteristics of patients in both groups are presented in Table 1. All of those parameters showed no significant differences between study groups except for the body temperature that was mildly elevated in group 1. 
Table 1

Baseline characteristics of patients

\begin{tabular}{|c|c|c|c|c|}
\hline & & Group $1(n=35)$ & Group $2(n=35)$ & p \\
\hline \multicolumn{2}{|l|}{ Female sex, n (\%) } & $24(68.6)$ & $22(62.9)$ & $>0.05$ \\
\hline \multicolumn{2}{|l|}{ Median age, years } & $78(64-82)$ & $77(71-82)$ & $>0.05$ \\
\hline \multicolumn{2}{|c|}{ Time since CHF diagnosis, months } & $65(48-138)$ & $64(49-125)$ & $>0.05$ \\
\hline \multicolumn{2}{|c|}{$\begin{array}{l}\text { Number of CHF worsening episodes during past } \\
\text { year }\end{array}$} & $2(1-2)$ & $2(1-2)$ & $>0.05$ \\
\hline \multirow[t]{3}{*}{ CHF functional class, n (\%) } & II & \multirow{3}{*}{$\begin{array}{l}21(60.0) \\
12(34.3) \\
2(5.7)\end{array}$} & \multirow{3}{*}{$\begin{array}{l}17(48.6) \\
17(48.6) \\
1(2.8)\end{array}$} & \multirow[t]{3}{*}{$>0.05$} \\
\hline & III & & & \\
\hline & IV & & & \\
\hline \multicolumn{2}{|l|}{ Cough, n (\%) } & $33(94.3)$ & $31(88.6)$ & $>0.05$ \\
\hline \multicolumn{2}{|l|}{ Sputum production, n (\%) } & $14(40)$ & $12(34.3)$ & $>0.05$ \\
\hline \multicolumn{2}{|l|}{ Dyspnea, n (\%) } & $35(100)$ & $35(100)$ & $>0.05$ \\
\hline \multicolumn{2}{|l|}{ Body temperature, ${ }^{\circ} \mathrm{C}$} & $\begin{array}{l}36.8(36.6- \\
37.2)\end{array}$ & $\begin{array}{l}36.4(36.3- \\
36.8)\end{array}$ & 0.0005 \\
\hline \multicolumn{2}{|l|}{ Edema, n (\%) } & $29(82.9)$ & $28(80)$ & $>0,05$ \\
\hline \multirow[t]{3}{*}{ Edema location, n (\%) } & Feet only & $4(13,8)$ & $8(28,6)$ & \multirow[t]{3}{*}{$>0.05$} \\
\hline & Feet and shins & $25(86,2)$ & $19(67,9)$ & \\
\hline & Anasarca & $0(0)$ & $1(3,5)$ & \\
\hline \multicolumn{2}{|c|}{ Fine crackles/rales on auscultation, $\mathrm{n}(\%)$} & $33(94.3)$ & $30(85.7)$ & $>0.05$ \\
\hline \multicolumn{2}{|c|}{ Dry rales on auscultation, $\mathrm{n}(\%)$} & $7(20)$ & $5(14.3)$ & $>0.05$ \\
\hline \multicolumn{2}{|c|}{ Infiltration on chest X-ray, n (\%) } & $28(80)$ & $32(91)$ & $>0.05$ \\
\hline \multicolumn{2}{|c|}{ Pleural effusion on chest X-ray, n (\%) } & $23(65.7)$ & $15(42.9)$ & $>0.05$ \\
\hline \multicolumn{2}{|c|}{ Peripheral WBC count $\left(\times 10^{9} \mathrm{~L}\right)$} & $8.4(7.0-11.2)$ & $8.3(7.0-9.5)$ & $>0.05$ \\
\hline \multicolumn{2}{|l|}{ Band neutrophils, n (\%) } & $7(5.0-9.8)$ & $6(1.0-10.0)$ & $>0.05$ \\
\hline \multicolumn{2}{|l|}{ In-hospital mortality, \% } & 2.9 & 2.9 & $>0.05$ \\
\hline
\end{tabular}

The results of the measurements of serum CRP, PCT, IL-6, TNF-a, and BNP concentrations are presented in Figs. 1-5. The value of CRP was 50.0 (35.5-98.5) vs 15.0 (9.5-25.0) mg/L in group 1 and group 2, respectively; the between-group comparisons showed significant differences. Serum PCT and IL-6 levels were also markedly elevated in patients with CAP during observation $-0.10(0.05-0.54) \mathrm{ng} / \mathrm{mL}$ and 46.1 
(21.4-150.3) $\mathrm{pg} / \mathrm{mL}$, respectively, and significantly different from those in control group $(\mathrm{p}<0.0001$ for both comparisons).

The results of measurements of TNFa are reflected in Fig. 4. There were no statistically significant differences in the concentrations of this biomarker during between-group comparisons with all median values in both groups being within the reference range.

Figure 5 shows BNP values. The concentration of BNP was 141.2 (51.6-362.1) $\mathrm{pg} / \mathrm{mL}$ in study group vs $117.6(47.8-256.8) \mathrm{pg} / \mathrm{mL}$ in control group. There were no differences in the values of this biomarker between the two groups.

After performing regression analyses using 5 individual models for each predictor, CRP ( $p=0.0001)$, PCT $(p=0.042)$, and IL-6 ( $p=0.003)$ demonstrated significant associations with the presence of CAP, while TNFa $(p=0.092)$ and BNP $(p=0.339)$ concentration did not bear any relationship to this diagnosis. Figure 6 (A-C) shows ROC-curve analysis results, showing discriminatory abilities for the promising biomarkers (CRP, PCT, and IL-6). Quantitatively we obtained the following AUC measures: $0.91(95 \% \mathrm{Cl}$ 0.83-0.98) for CRP, 0.81 (95\% Cl 0.72-0.90) for PCT, and 0.81 (0.71-0.91) for IL-6. Thus, the diagnostic accuracy of CRP can be considered excellent (AUC $\geq 0.90$ ), while PCT and IL-6 demonstrated good discrimination ( $A U C \geq 0.80$ ).

We measured the optimal cut-off values for the aforementioned biomarkers, allowing to confirm/exclude CAP with adequate sensitivity and specificity in the population of patients with coexisting CHF. Selected concentrations of each predictor with respective efficacy measures are presented in Table 2. 
Table 2

Sensitivities and specificities of selected cut-off values of most promising biomarkers for diagnosis of CAP in CHF patients

\begin{tabular}{|c|c|c|c|c|c|c|c|c|}
\hline CRP & & & РCT & & & IL-6 & & \\
\hline $\begin{array}{l}\text { Sn } \\
(\%)\end{array}$ & $\begin{array}{l}\mathrm{Sp} \\
(\%)\end{array}$ & $\begin{array}{l}\text { Cut-off } \\
\text { (mg/L) }\end{array}$ & $\begin{array}{l}\text { Sn } \\
(\%)\end{array}$ & $\begin{array}{l}\text { Sp } \\
(\%)\end{array}$ & $\begin{array}{l}\text { Cut-off } \\
\text { (ng/mL) }\end{array}$ & $\begin{array}{l}\text { Sn } \\
(\%)\end{array}$ & $\begin{array}{l}\text { Sp } \\
(\%)\end{array}$ & $\begin{array}{l}\text { Cut-off } \\
(\mathrm{pg} / \mathrm{mL})\end{array}$ \\
\hline 100.0 & 8.6 & 3.5 & 68.6 & 85.7 & 0.050 & 88.6 & 48.6 & 13.3 \\
\hline 97.1 & 11.4 & 5.0 & 62.9 & 91.4 & 0.055 & 85.6 & 48.6 & 13.5 \\
\hline 94.3 & 11.4 & 7.0 & 60.0 & 91.4 & 0.065 & 85.7 & 51.4 & 13.9 \\
\hline 94.3 & 25.7 & 9.5 & 60.0 & 94.3 & 0.075 & 82.9 & 54.3 & 14.4 \\
\hline 94.3 & 34.3 & 11.5 & 57.1 & 97.1 & 0.085 & 82.9 & 57.1 & 15.1 \\
\hline 94.3 & 48.6 & 14.5 & 54.3 & 97.1 & 0.095 & 82.9 & 60.0 & 15.9 \\
\hline 94.3 & 57.1 & 17.5 & 48.6 & 97.1 & 0.115 & 80.0 & 62.9 & 18.7 \\
\hline 94.3 & 68.6 & 21.0 & 48.6 & 100.0 & 0.145 & 74.3 & 65.7 & 20.2 \\
\hline 91.4 & 71.4 & 23.5 & 45.7 & 100.0 & 0.185 & 74.3 & 68.6 & 21.5 \\
\hline 88.6 & 71.4 & 24.5 & 42.9 & 100.0 & 0.220 & 74.3 & 74.3 & 23.9 \\
\hline 85.7 & 85.7 & 25.5 & 40.0 & 100.0 & 0.235 & 71.4 & 77.1 & 26.3 \\
\hline 85.7 & 88.6 & 26.5 & 37.1 & 100.0 & 0.265 & 71.4 & 82.9 & 27.6 \\
\hline 85.7 & 91.4 & 28.5 & 34.3 & 100.0 & 0.335 & 65.7 & 82.9 & 28.4 \\
\hline 80.0 & 91.4 & 31.5 & 31.4 & 100.0 & 0.395 & 60.0 & 82.9 & 31.9 \\
\hline 77.1 & 91.4 & 33.5 & 28.6 & 100.0 & 0.460 & 60.0 & 85.7 & 35.7 \\
\hline 74.3 & 94.3 & 35.5 & 25.7 & 100.0 & 0.545 & 57.1 & 88.6 & 39.3 \\
\hline 71.4 & 94.3 & 38.0 & 22.6 & 100.0 & 0.945 & 54.3 & 91.4 & 42.5 \\
\hline 68.6 & 97.1 & 40.5 & 20.0 & 100.0 & 1.355 & 51.4 & 91.4 & 44.3 \\
\hline 62.9 & 97.1 & 45.0 & 17.1 & 100.0 & 2.255 & 48.6 & 94.3 & 49.9 \\
\hline 60.0 & 97.1 & 48.0 & 14.3 & 100.0 & 3.845 & 48.6 & 97.1 & 58.5 \\
\hline 45.7 & 97.1 & 54.0 & 11.4 & 100.0 & 5.855 & 42.9 & 98.1 & 67.7 \\
\hline 42.9 & 97.1 & 60.0 & 8.6 & 100.0 & 8.665 & 42.9 & 100.0 & 78.8 \\
\hline 40.0 & 100.0 & 64.0 & 5.7 & 100.0 & 14.44 & 40.0 & 100.0 & 87.3 \\
\hline
\end{tabular}




\begin{tabular}{|c|c|c|c|c|c|c|c|c|}
\hline \multicolumn{3}{|l|}{ CRP } & \multicolumn{3}{|c|}{ PCT } & \multicolumn{3}{|l|}{ IL-6 } \\
\hline 37.1 & 100.0 & 67.0 & 2.9 & 100.0 & 27.56 & 37.1 & 100.0 & 88.9 \\
\hline
\end{tabular}

\section{Discussion}

The challenges of CAP diagnosis in the presence of concomitant CHF can be attributed to the difficulties of assessment of symptoms common to both cardiovascular and respiratory diseases (2). Routine laboratory diagnosis of CAP in CHF patients is fraught with some difficulties, since systemic inflammatory response can be variable $(6,9,10)$.

Conventional chest X-ray is still considered the standard diagnostic method for CAP (11). However, the rate of misdiagnosis in adults with the presumptive diagnosis of CAP reaches $30 \%$ and increases with age (5). In our study infiltration on chest X-ray was visualized in the majority of patients and did not differ between groups which is consistent with the previously published data (9).

CRP is the most studied marker of bacterial inflammation and one of the most validated diagnostic laboratory tests in clinical practice worldwide (12). In our study, $97 \%$ of patients with CAP had at least a twofold elevation of the serum CRP level above reference values. The median serum CRP concentration was relatively low compared to data obtained by other authors, while the values typically exceed $100 \mathrm{mg} / \mathrm{L}$ in the presence of systemic bacterial infections (13). These findings may be attributed to the age-related dysregulation of pro- and anti-inflammatory mediators and the consequent disruption of protein synthesis in hepatocytes in the elderly patients who prevailed in our study. An alternative hypothesis could be the stimulating action of CHF state on the basal CRP production with subsequent depletion of its inducible secretion in response to the action of infectious agent during the development of CAP. It is worth mentioning that we recruited patients with non-severe CAP.

However, hypersecretion of CRP is registered during other conditions including CHF $(14,15)$. Serum CRP in patients with excluded CAP was also elevated in our study, with median value as high as 15.0 (9.5-25.0) $\mathrm{mg} / \mathrm{L}$. The between-group differences were statistically significant, pointing out to the possible use of this biomarker as a means of CAP verification in the presence of concomitant CHF. Other authors obtained similar results $(6,10)$. Thus, in study by Lee Y.J. et al. CRP was used as part of differentiated diagnosis of bilateral lung infiltrates causes on chest $X$-ray: in patients with cardiac congestion measured 12 (0.4247.4) $\mathrm{mg} / \mathrm{L}$, while in patients with respiratory disease its values amounted to $103(0.2-464.9) \mathrm{mg} / \mathrm{L}(10)$. According to Cha Y.S. et al., the median CRP concentrations in patients with pneumonia and acute decompensated CHF greatly exceed those in patients with isolated $\mathrm{CHF}(61.0 \mathrm{mg} / \mathrm{dL}$ vs $5.6 \mathrm{mg} / \mathrm{L}, \mathrm{p}<$ 0.001) (1).

Regression analysis confirmed the diagnostic value of CRP for the prediction of CAP in CHF patients with excellent discriminatory ability (AUC $=0.91 ; 95 \% \mathrm{Cl} 0.83-0.98)$. Our results match those previously 
demonstrated by other authors $(6,9,12,13,16-18)$. CRP had an acceptable classification accuracy in the verification of pneumonia and the differential diagnosis from other respiratory and non-respiratory diseases $(6,13)$.

Alongside CRP, PCT is a more specific biomarker of acute generalized bacterial inflammation (19). Overproduction of PCT, associated with development of pneumonia, has been previously described, however the exact values differed significantly $(12,20,21)$. The baseline level of PCT, identified in our study, can be regarded as relatively high for the given pathology. This parameter turned out to be highly variable and exceeded $2 \mathrm{ng} / \mathrm{mL}$ in only $17 \%$ of our study participants. The results obtained from our cohort of patients could be attributed to the recruitment of patients with non-severe CAP.

PCT readings in CHF patients are also variable: from $0.09(0.06-0.16)$ to $1.3(0.89-1.8) \mathrm{ng} / \mathrm{mL}](2,7,22)$. Our results concur with the latter findings: PCT measurements in CHF patients without CAP were lower than $0.1 \mathrm{ng} / \mathrm{mL}$ in almost all cases.

Such contradictory findings can be attributed to the differences in baseline characteristics of CHF patients. Significant PCT elevation may be due to the predominance of patients with marked left ventricular (LV) systolic dysfunction in those samples $(22,23)$. In our study, conversely, $11 \%$ of participants had preserved LV systolic function, while the other $89 \%$ of patients had mildly decreased LV contractility (median ejection fraction, $44(40.0-47.5) \%)(4)$.

Regression analysis demonstrated high PCT efficacy for the diagnosis of CAP in CHF patients: AUC = 0.81 ( $95 \% \mathrm{Cl} 0.72-0.90), \mathrm{p}=0.042$. According to the literature, the predicting value of PCT for the diagnosis of CAP in different patient populations is, nevertheless, relatively variable $(2,8,12,17,18,24)$. In one study, the measurement of PCT in addition to clinical model significantly increased its accuracy (AUC $=0.79(95 \% \mathrm{Cl} 0.75-0.83)$ vs AUC $=0.88(95 \% \mathrm{Cl} 0.85-0.91), \mathrm{p}<0.001)$, while it did not prove to be useful in another work (AUC $=0.70(95 \% \mathrm{Cl} 0.65-0.75)$ vs AUC $=0.71(95 \% \mathrm{Cl} 0.67-0.76), \mathrm{p}>0.05)$ $(18,24)$. Significance of PCT as a predictor of low RTI/CAP in CHF patients varied from AUC $=0.72$ to AUC $₫ 0.8$, being, in general, comparable to the results of our study $(2,8)$.

IL-6 is a typical proinflammatory cytokine, which is elevated in various infectious and non-infectious diseases (25). Its mean concentration increases in CAP cases in the range from $48 \mathrm{pg} / \mathrm{mL}$ to $3569 \mathrm{pg} / \mathrm{mL}$, being highly variable due to different study designs, although not usually exceeding $300 \mathrm{pg} / \mathrm{mL}$ in heterogenous populations of pneumonia patients $(7,26)$. The baseline value of this parameter in our study also considerably exceeded the reference range $(0-10 \mathrm{pg} / \mathrm{mL})$. This result corresponds to literature data, but high standard deviation reflects limits for the diagnostic value of IL- 6 .

The role of cytokines, including IL-6, in the realization of molecular mechanisms of cardiac dysfunction has been proven (27). Thus, the concentrations of this biomarker in CHF varied from normal to markedly increased $(28,29)$. However, in the majority of published studies this parameter measured only $10-$ $15 \mathrm{pg} / \mathrm{mL}$, slightly out of the reference range $(0-10 \mathrm{pg} / \mathrm{mL})(29,30)$. 
The baseline IL-6 level in our study exceeded reference values, but matched the previously mentioned diapason. Consequently, our results may be caused by other concomitant respiratory infections (mostly viral), initially diagnosed in some patients and not associated with pneumonia.

On comparison, the IL- 6 level was significantly higher in the group of patients with CAP than in those CHF patients without CAP. A similar tendency was found in studies of Mueller T., et al and Wang W., et al $(7,8)$. The diagnostic value of IL- 6 in the algorithm for CAP verification in concomitant CHF was shown using logistic regression. Its discriminatory accuracy was good (AUC $=0.81 ; 95 \% \mathrm{Cl} 0.72-0.90)$.

TNFa is a multifunctional proinflammtory cytokine, dysregulation of which is characteristic for a lot of diseases (31). In CAP patients in comparison with reference values the published results ranged from being close to normal $(7.6(5.8-14.4) \mathrm{pg} / \mathrm{mL})$ to greatly elevated $(56.1 \pm 80.44 \mathrm{pg} / \mathrm{mL})(33,34)$. In our study TNFa concentrations in confirmed CAP demonstrated marked variability, but remained within the reference range. Predominance of non-severe CAP could explain these results. However, in another study, TNFa level for surviving patients was low $(6.1 \pm 5.0 \mathrm{pg} / \mathrm{mL})$ even in severe CAP (32).

The role of TNFa in the pathogenesis of CHF has been demonstrated before, but degree of its effect on the development and progression of the disease is not yet completely determined $(33,34)$. Normal and elevated mean values of biomarker in CHF were detected in relevant studies with similar frequency $(33,35)$. In our study TNFa levels were comparable in both groups. Regression analysis confirmed the inefficacy of this biomarker for algorithm of CAP verification in comorbid CHF.

BNP is considered to be the 'gold-standard' biomarker of CHF development and progression, although its concentration could rise in other illnesses as well, while still being associated with cardiovascular injury in most cases. The variability of published results in CAP (mean BNP level from $26 \pm 15 \mathrm{pg} / \mathrm{mL}$ to $273 \pm$ $360 \mathrm{pg} / \mathrm{mL}$ ) could be attributed to the presence of concomitant CHF in a certain proportion of patients, as they were not formally excluded from such studies $(7,36,37)$.

Due to the design of our study and inclusion of patients with CAP and confirmed CHF only, serum BNP concentrations were logically elevated and amounted to 141.2 (51.6-362.1) pg/mL (reference range 0-80 (100) $\mathrm{pg} / \mathrm{mL}$ depending on the age of the patient).

Similar results were obtained in the group of $\mathrm{CHF}$ patients without CAP. The literature data demonstrate wide variation of this parameter in patients with $\mathrm{CHF}(36,38)$. This phenomenon is attributed to the interindividual variability of BNP levels in different CHF populations, determined by the type, stage, and the degree of CHF compensation, extracardiac factors and other diseases $(30,39,40)$.

The BNP values obtained for CHF patients in our study, irrespective of the presence of CAP, did not deviate from the previously mentioned range of mean values. The lack of difference in BNP readings points to the futility of its additional use for CAP diagnostics in this patient category. Similar results were obtained in regression analysis of biomarker predicting ability. 
According to the results of our study, the most effective predictor of CAP presence in patients with concomitant CHF by all criteria was CRP. The diagnostic value of PCT and IL- 6 was considered to be inadequate as both these biomarkers are characterized by marked inter-individual variability of the measurements. Furthermore, the increases in the specificity of PCT and IL- 6 assessments were accompanied by the drastic decreases in sensitivity, which is unacceptable in this patient category.

In our study, the CRP value of $>28.5 \mathrm{mg} / \mathrm{L}$ was an optimal cut-off to verify CAP in patients with concomitant CHF with $85.7 \%$ sensitivity and $91.4 \%$ specificity. It should be noted, however, that this was relatively low in comparison to those obtained by other authors. A number of authors suggested different cut-off values for the diagnosis of CAP in uni- and multivariable models with varying measures of overall efficacy $(12,13,17,18,24,41-44)$. Cut-off value of $50 \mathrm{mg} / \mathrm{L}$ is most widely reported, although its sensitivity/specificity ratio varied between different studies: $87 \% / 65 \%$ (clinical model without considering radiological diagnostic methods), $94 \% / 72 \%$ (model allowing to decrease the rate of inappropriate antibiotic use in low RTI), 74\%/96\% (differential diagnosis of CAP and non-specific low RTIs), 50\%/89\% (differential diagnosis between pulmonary tuberculosis and $\operatorname{CAP}(12,18,42,43)$. Same authors also suggested higher CRP cut-off values (100-200 mg/L), allowing to confirm or exclude the presence of pneumonia with various sensitivity and specificity $(12,13,18,43,44)$.

Limitation of our study was a relatively small sample size.

\section{Conclusions}

Clinical features of CAP in CHF hamper the diagnostic process, providing the impetus for the search of novel affordable, effective and safe confirmatory diagnostic methods. Such serum biomarkers as CRP, PCT and IL- 6 were significantly elevated in CAP in comparison to isolated CHF. Measurement of TNFa and BNP in this scenario has no practical value. CRP was proven to be the most useful diagnostic biomarker according to the results of regression analysis, with elevation of $>28.5 \mathrm{mg} / \mathrm{L}$ being able to verify the presence of CAP in patients with concomitant CHF with high sensitivity (85.7\%) and specificity (91.4\%). Therefore CRP measurement could be considered as a means of optimization of diagnosis of CAP in patients with concomitant $\mathrm{CHF}$ in addition to routine algorithm.

\section{List Of Abbreviations}

(AUC) Area Under ROC Curve

(BNP) Brain natriuretic peptide

(CRP) C-reactive protein

(CAP) Community-acquired pneumonia

(CHF) Chronic heart failure 
(IL-6) Interleukin-6

(IQR) Interquartile range

(LV) Left ventricular

(MSCT) Multispiral computed tomography

(PCT) Procalcitonin

(ROC) Receiver Operation Characteristic

(RTI) Respiratory tract infection

(TNFa) Tumour necrosis factor a

(X-ray) Radiography

\section{Declarations}

Ethics approval and consent to participate: The protocol of the study was approved by the local institutional review board. Upon enrollment and prior to any procedure relevant to the study, each participant signed two copies of the informed consent form.

Consent for publication: Not applicable.

Availability of data and materials: The datasets used and/or analysed during the current study are available from the corresponding author on reasonable request.

Competing interests: The authors declare that they have no competing interests.

Funding: Not applicable.

Authors' contributions: A. Bobylev - conception and design, provision of study materials of patient, collection and assembly of data, data analysis and interpretation, manuscript writing, final approval of manuscript, S. Rachina - conception and design, data analysis and interpretation, manuscript writing, final approval of manuscript, S. Avdeev - data analysis and interpretation, administrative support, manuscript writing, final approval of manuscript, R. Kozlov - administrative support, provision of study materials of patient, manuscript writing, final approval of manuscript, P. Lazarev - data analysis and interpretation, manuscript writing, final approval of manuscript, V. Mladov - conception and design, data analysis and interpretation, manuscript writing, final approval of manuscript, Y. Khruleva - manuscript writing, final approval of manuscript.

Acknowledgements: Not applicable. 


\section{References}

(1) Cha Y, Lee K, Lee J, et al. The Usefulness of the Delta Neutrophil Index for Predicting Superimposed Pneumonia in Patients with Acute Decompensated Heart Failure in the Emergency Department. PLOS ONE 2016;11(9):e0163461.

(2) Maisel A, Neath S, Landsberg J, et al. Use of procalcitonin for the diagnosis of pneumonia in patients presenting with a chief complaint of dyspnoea: results from the BACH (Biomarkers in Acute Heart Failure) trial. European Journal of Heart Failure 2012;14(3):278-286.

(3) Mueller C, Scholer A, Laule-Kilian K, et al. Use of B-Type Natriuretic Peptide in the Evaluation and Management of Acute Dyspnea. New England Journal of Medicine 2004;350(7):647-654.

(4) Ponikowski P, Voors A, Anker S, et al. 2016 ESC Guidelines for the diagnosis and treatment of acute and chronic heart failure. European Heart Journal 2016;37(27):2129-2200.

(5) Kanwar M, Brar N, Khatib R, et. al. Misdiagnosis of Community-Acquired Pneumonia and Inappropriate Utilization of Antibiotics. Chest 2007;131(6):1865-1869.

(6) Joffe E, Justo D, Mashav N, et al. C-reactive protein to distinguish pneumonia from acute decompensated heart failure. Clinical Biochemistry 2009;42(16-17):1628-1634.

(7) Mueller T, Leitner I, Egger M, et. al. Association of the biomarkers soluble ST2, galectin-3 and growth-differentiation factor- 15 with heart failure and other non-cardiac diseases. Clinica Chimica Acta 2015;445:155-160.

(8) Wang W, Zhang X, Ge N, et al. Procalcitonin testing for diagnosis and short-term prognosis in bacterial infection complicated by congestive heart failure: a multicenter analysis of 4,698 cases. Critical Care 2014;18(1):R4.

(9) Lee YJ, Lee J, Park YS, et al. Predictors of Cardiogenic and Non-Cardiogenic Causes in Cases with Bilateral Chest Infiltrates. Tuberculosis and Respiratory Diseases 2013;74(1):15.

(10) Zalacain R, Torres A, Celis R, et al. Community-acquired pneumonia in the elderly: Spanish multicentre study. European Respiratory Journal 2003;21(2):294-302.

(11) Lim W.S., Baudouin S.V., George R.C., et al. BTS guidelines for the management of community acquired pneumonia in adults: update 2009. Thorax 2009;64(Suppl 3):iii1-iii55.

(12) Kang YA, Kwon SY, Yoon HIL, et al. Role of C-Reactive Protein and Procalcitonin in Differentiation of Tuberculosis from Bacterial Community Acquired Pneumonia. The Korean Journal of Internal Medicine 2009;24(4):337. 
(13) Flanders SA, Stein J, Shochat G, et al. Performance of a bedside c-reactive protein test in the diagnosis of community-acquired pneumonia in adults with acute cough. The American Journal of Medicine 2004;116(8):529-535.

(14) Moon J, Kang S-M, Cho IJ, et al. Clinical and Echocardiographic Findings of Newly Diagnosed Acute Decompensated Heart Failure in Elderly Patients. Yonsei Medical Journal 2011;52(1):33.

(15) Matsubara J, Sugiyama S, Nozaki T, et al. Pentraxin 3 Is a New Inflammatory Marker Correlated With Left Ventricular Diastolic Dysfunction and Heart Failure With Normal Ejection Fraction. Journal of the American College of Cardiology 2011;57(7):861-869.

(16) Steurer J, Held U, Spaar A, et al. A decision aid to rule out pneumonia and reduce unnecessary prescriptions of antibiotics in primary care patients with cough and fever. BMC Medicine 2011;9(1).

(17) Bafadhel M, Clark TW, Reid C, et al. Procalcitonin and C-Reactive Protein in Hospitalized Adult Patients With Community-Acquired Pneumonia or Exacerbation of Asthma or COPD. Chest 2011;139(6):1410-1418.

(18) Müller B, Harbarth S, Stolz D, et al. Diagnostic and prognostic accuracy of clinical and laboratory parameters in community-acquired pneumonia. BMC Infectious Diseases 2007;7(1).

(19) Foushee J, Hope N, Grace E. Applying biomarkers to clinical practice: a guide for utilizing procalcitonin assays. Journal of Antimicrobial Chemotherapy 2012;67(11):2560-2569.

(20) Kim JH, Seo JW, Mok JH, et al. Usefulness of Plasma Procalcitonin to Predict Severity in Elderly Patients with Community-Acquired Pneumonia. Tuberculosis and Respiratory Diseases 2013;74(5):207.

(21) Horie M, Ugajin M, Suzuki M, et al. Diagnostic and Prognostic Value of Procalcitonin in Community-Acquired Pneumonia. The American Journal of the Medical Sciences 2012;343(1):30-35.

(22) Kafkas N, Venetsanou K, Patsilinakos S, et al. Procalcitonin in acute myocardial infarction. Acute Cardiac Care 2008;10(1):30-36.

(23) Buratti T, Ricevuti G, Pechlaner C, et al. Inflammation 2001;25(2):97-100.

(24) Van Vugt SF, Broekhuizen BDL, Lammens C, et al. Use of serum C reactive protein and procalcitonin concentrations in addition to symptoms and signs to predict pneumonia in patients presenting to primary care with acute cough: diagnostic study. BMJ 2013;346(apr30 1):f2450-f2450.

(25) Derosa G, Maffioli P, Simental-Mendía LE, et al. Effect of curcumin on circulating interleukin-6 concentrations: A systematic review and meta-analysis of randomized controlled trials. Pharmacological Research 2016;111:394-404. 
(26) Calbo E, Alsina M, Rodríguez-Carballeira $M$, et al. The impact of time on the systemic inflammatory response in pneumococcal pneumonia. European Respiratory Journal 2009;35(3):614618.

(27) Blum A, Miller H. Role of cytokines in heart failure. American Heart Journal 1998;135(2):181186.

(28) Kinugawa T, Kato M, Yamamoto K, et al. Proinflammatory Cytokine Activation Is Linked to Apoptotic Mediator, Soluble Fas Level in Patients With Chronic Heart Failure. International Heart Journal 2012;53(3):182-186.

(29) Stanciu $A E$, Vatasescu RG, Stanciu MM, et al. Cardiac resynchronization therapy in patients with chronic heart failure is associated with anti-inflammatory and anti-remodeling effects. Clinical Biochemistry 2013;46(3):230-234.

(30) Matsumoto M, Tsujino T, Lee-Kawabata M, et al. Serum interleukin- 6 and C-reactive protein are markedly elevated in acute decompensated heart failure patients with left ventricular systolic dysfunction. Cytokine 2010;49(3):264-268.

(31) Männel DN, Echtenacher B. TNF in the Inflammatory Response. CD14 in the Inflammatory Response 1999;74:141-161.

(32) Lee Y-L, Chen W, Chen L-Y, et al. Systemic and bronchoalveolar cytokines as predictors of inhospital mortality in severe community-acquired pneumonia. Journal of Critical Care 2010;25(1):176.e7-176.e13.

(33) Fink AM, Gonzalez RC, Lisowski T, et al. Fatigue, Inflammation, and Projected Mortality in Heart Failure. Journal of Cardiac Failure 2012;18(9):711-716.

(34) Niethammer M, Sieber M, von Haehling S, et al. Inflammatory pathways in patients with heart failure and preserved ejection fraction. International Journal of Cardiology 2008;129(1):111-117.

(35) Peschel T, Schönauer $M$, Thiele $H$, et al. Invasive assessment of bacterial endotoxin and inflammatory cytokines in patients with acute heart failure. European Journal of Heart Failure 2003;5(5):609-614.

(36) Parab R, Vasudevan A, et al. Utility of Brain Natriuritic Peptide as a Diagnostic Tool for Congestive Heart Failure in the Elderly. Critical Pathways in Cardiology: A Journal of Evidence-Based Medicine 2005;4(3):140-144.

(37) An J-D, Zhang Y-P, Zhou J-H. Levels of serum brain natriuretic peptide in children with congestive heart failure or with severe pneumonia. Zhongguo Dang Dai Er Ke Za Zhi 2006; 8(3):2014. 
(38) Wang Y, Zhou Y, Meng L, et al. Inflammatory Mediators in Chinese Patients With Congestive Heart Failure. The Journal of Clinical Pharmacology 2009;49(5):591-599.

(39) Boffa GM, Zaninotto M, Sartor R, et al. Interleukin-6 and tumor necrosis factor-a as biochemical markers of heart failure: a head-to-head clinical comparison with B-type natriuretic peptide. Journal of Cardiovascular Medicine 2009;10(10):758-764.

(40) de Denus S, Lavoie J, Ducharme A, et al. Differences in Biomarkers in Patients With Heart Failure With a Reduced vs a Preserved Left Ventricular Ejection Fraction. Canadian Journal of Cardiology 2012;28(1):62-68.

(41) Almirall J, Bolíbar I, Toran P, et al. Contribution of C-Reactive Protein to the Diagnosis and Assessment of Severity of Community-Acquired Pneumonia. Chest 2004;125(4):1335-1342.

(42) Holm A, Pedersen SS, Nexoe J, et al. Procalcitonin versus C-reactive protein for predicting pneumonia in adults with lower respiratory tract infection in primary care. $\mathrm{Br} \mathrm{J}$ Gen Pract 2007; 57(540):555-60.

(43) Stolz D, Christ-Crain M, Gencay MM, et al. Diagnostic value of signs, symptoms and laboratory values in lower respiratory tract infection. Swiss Med Wkly 2006;136(27-28):434-40

(44) Melbye H, Straume B, Aasebø U, et al. The Diagnosis of Adult Pneumonia in General Practice:The Diagnostic Value of History, Physical Examination and Some Blood Tests. Scandinavian Journal of Primary Health Care 1988;6(2):111-117.

\section{Figures}




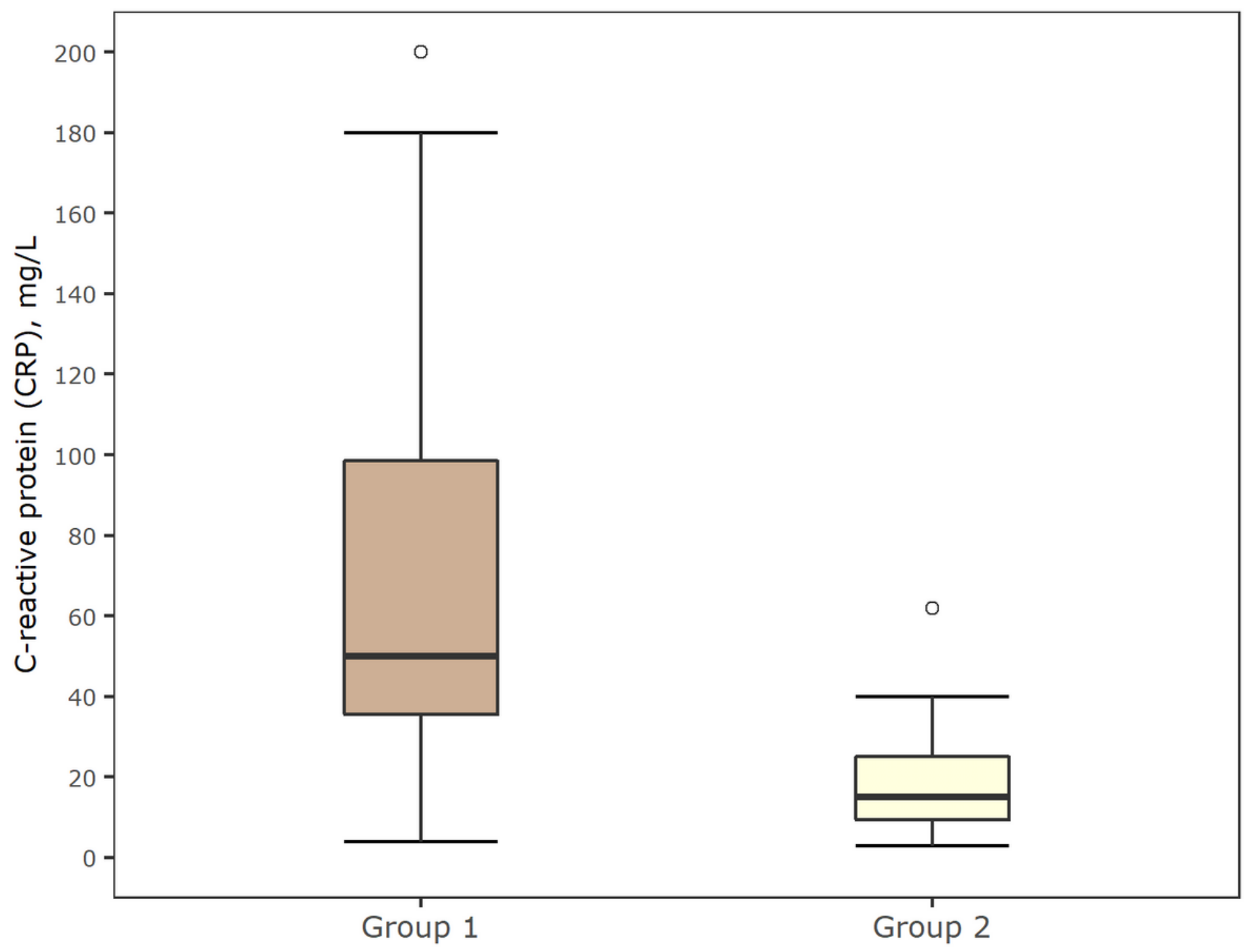

Figure 2

Serum CRP concentration in patients with (group 1) or without (group 2) CAP 


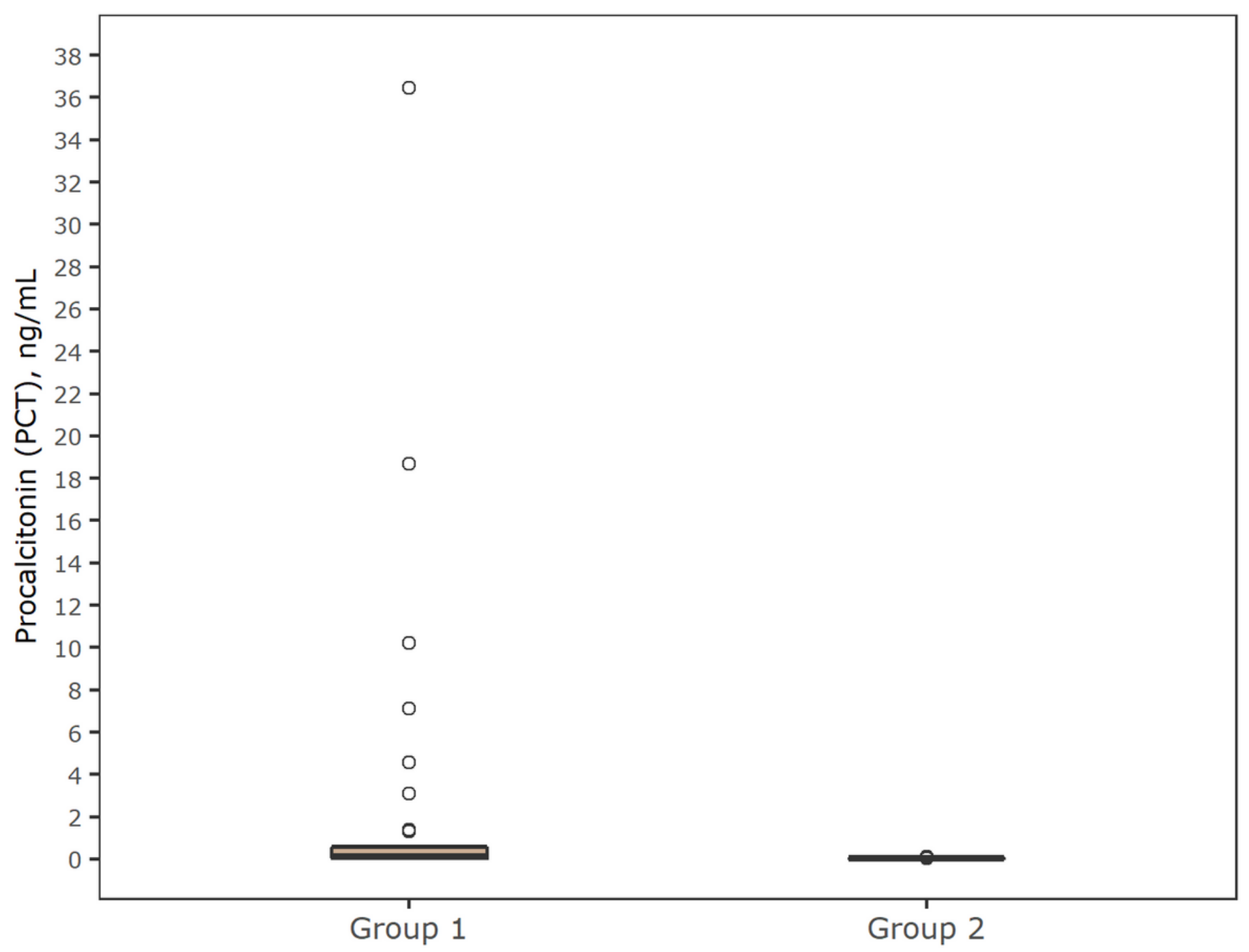

Figure 4

Serum PCT concentration in patients with (group 1) or without (group 2) CAP 


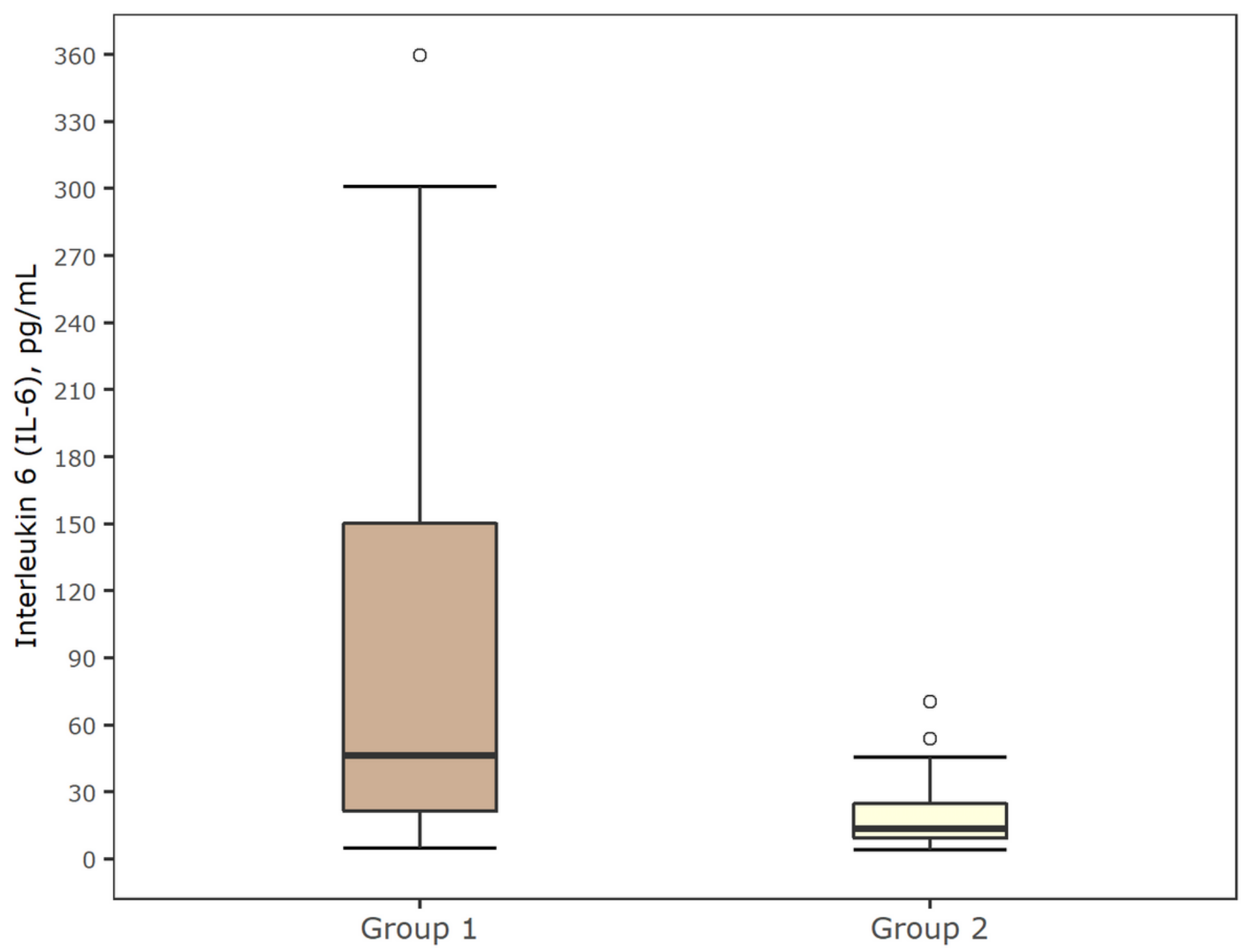

Figure 6

Serum IL-6 concentration in patients with (group 1) or without (group 2) CAP 


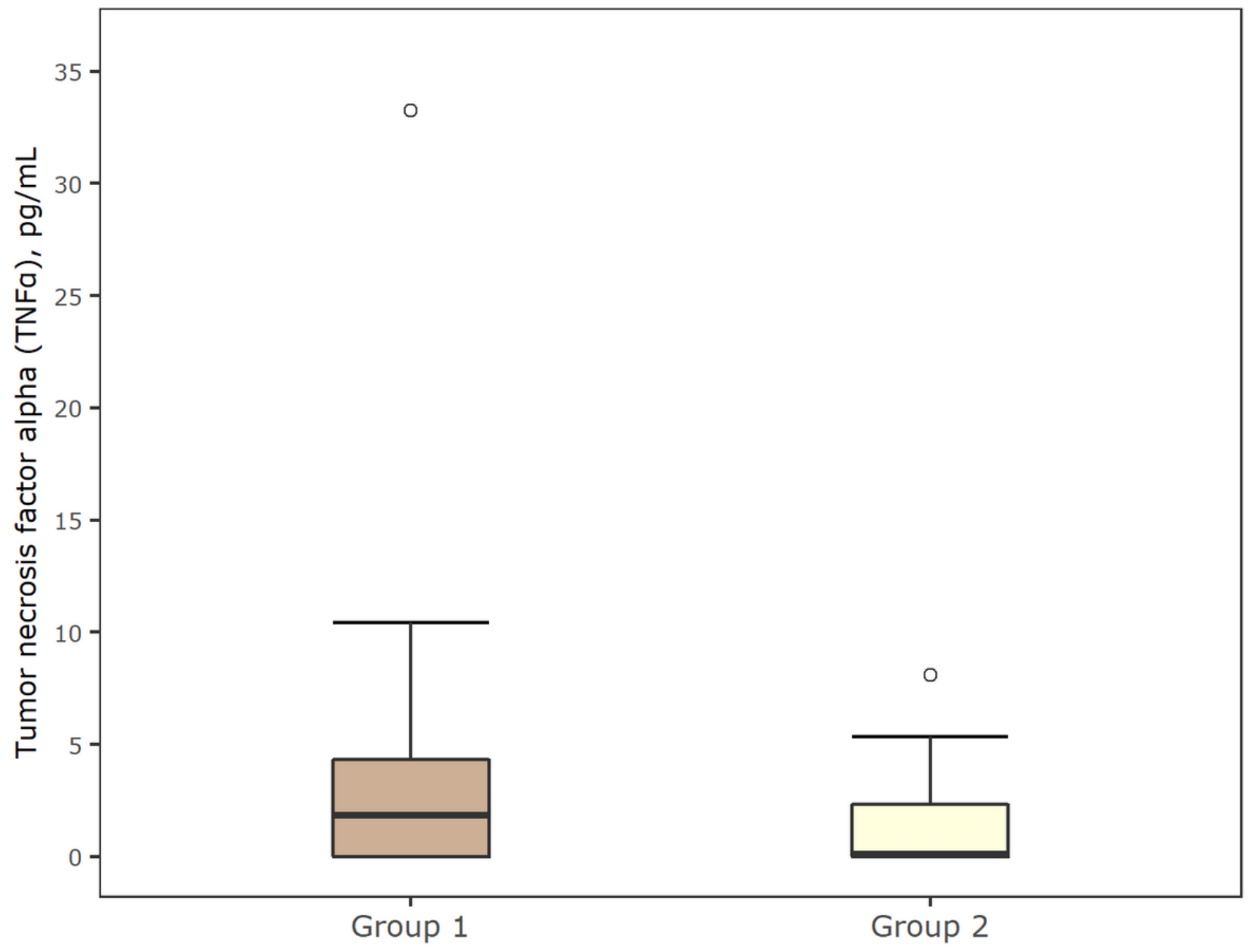

Figure 8

Serum TNFa concentration in patients with (group 1) or without (group 2) CAP 


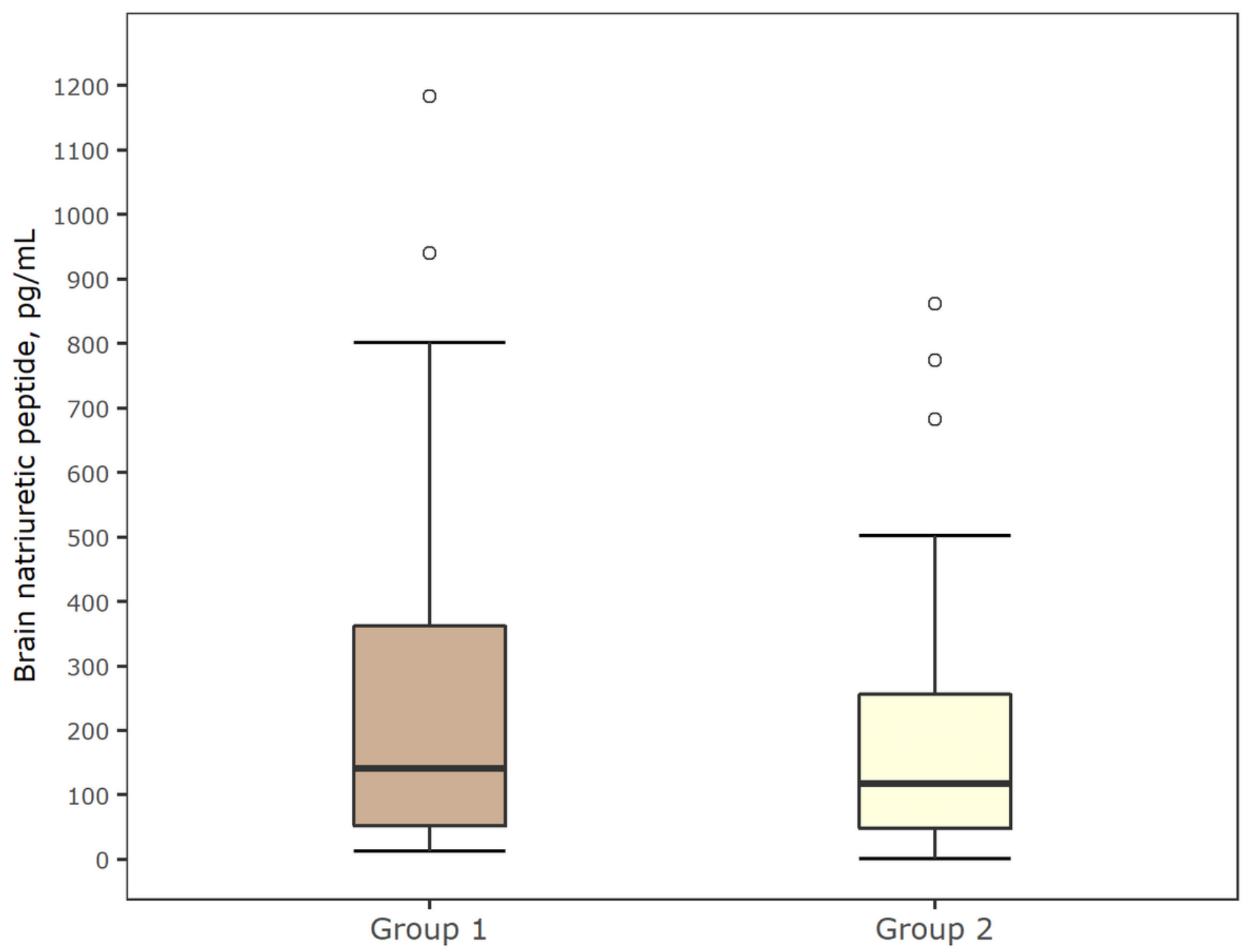

Figure 10

Serum BNP concentration in patients with (group 1) or without (group 2) CAP

A

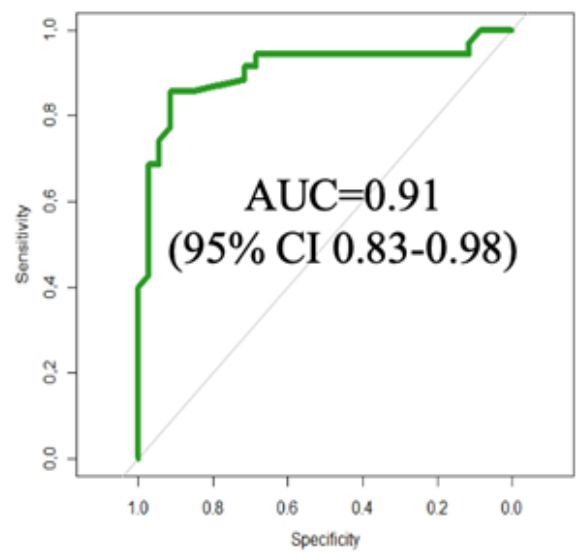

B

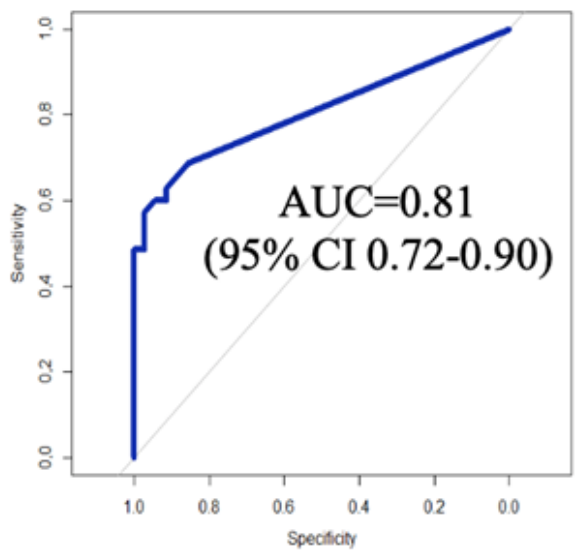

C

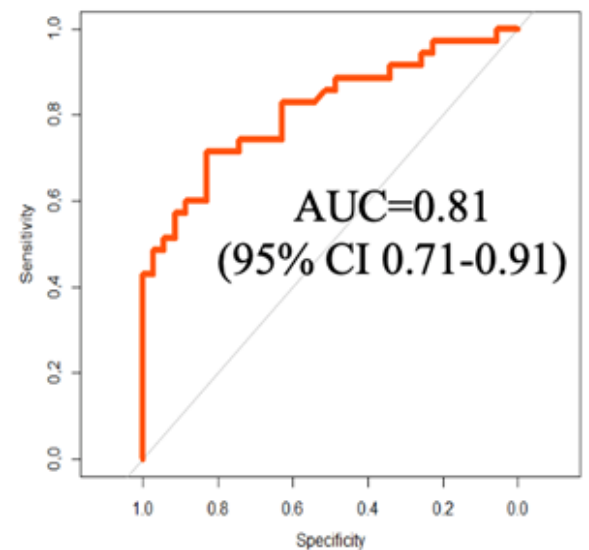


Figure 12

ROC-curve showing the discriminatory value of CRP (A), PCT (B), IL-6 (C) for the prediction of CAP in CHF patients 